\title{
O determinismo agrícola na arqueologia amazônica
}

\author{
CLAIDE DE PAULA MORAES ${ }^{I}$
}

$\mathrm{N}$ A AMAZÔNIA central, região convencionalmente definida como o baixo curso dos rios Solimões e Negro até as proximidades da foz do rio Madeira, no estado do Amazonas, os sítios arqueológicos apresentam evidências de que por volta do ano mil de nossa era grandes contingentes populacionais se estabeleceram deixando evidências em diversos sítios arqueológicos (Moraes; Neves, 2012). Alguns dos sítios arqueológicos que mencionaremos neste texto, como Vila Gomes, Hatahara e Açutuba (Figura 1), seriam exemplos de evidências de assentamentos humanos de grandes proporções datados desse período. Data também da mesma época o processo mais intenso de formação de terra preta nos depósitos arqueológicos. A terra preta de índio é um vestígio bastante estudado na arqueologia amazônica e vem sendo utilizada como indicador de sedentarismo, grandes aglomerados de pessoas (Petersen et al., 2001) e mesmo como evidência da possibilidade de práticas agrícolas de larga escala na Amazônia antiga (Sombröek, 1966; Glaser et al., 2001; Rebellato; Woods, 2012).

Do início do segundo milênio da era cristã até a chegada dos primeiros europeus parece ter havido uma diminuição do contingente populacional nas ocupações. Os vestígios arqueológicos apontam um colapso de vários sistemas regionais que pareciam apresentar grandes aglomerados de pessoas. Quais seriam as causas desse colapso?

Por volta do século XII o emergente padrão político regional visto na Amazônia central durante o que nós, arqueólogos, convencionamos chamar de fase Paredão entra em decadência.

O primeiro arqueólogo a mencionar as evidências dos vestígios legados pelos antigos habitantes da região de Manaus foi Peter Paul Hilbert que nos anos 1950 identificou um estilo cerâmico nomeado fase Paredão. Na classificação proposta na época os vestígios da fase Paredão faziam parte do segundo momento da sequência de ocupação da Amazônia Central. Hilbert (1968) organizou os vestígios encontrados na Amazônia Central em fase Manacapuru, fase Paredão, fase Guarita e fase Itacoatiara. Lima (2008) dividiu a fase Manacapuru em duas, nomeando o período mais antigo de fase Açutuba.

Na ocupação da fase Paredão os grupos que habitaram a Amazônia central adotaram uma estratégia bastante diferente de seus predecessores, e mesmo de seus sucessores. Enquanto nas ocupações Açutuba, Manacapuru e Guarita os 
vestígios podem ser identificados em vastas regiões, no caso de Manacapuru e uma série de fases regionais diferentes como Itacoatiara, Pocó, Caiambé e cerâmicas das séries Saladoide e Barrancoide da Venezuela muitos paralelos podem ser traçados demonstrando uma vasta dispersão regional (Lathrap, 1970; Guapindaia, 2008; Lima, 2008). No caso das cerâmicas policromas Guarita, padronização formal, decorativa e contemporaneidade podem ser encontradas desde o rio Madeira e o baixo Amazonas até o rio Napo (Evans; Meggers, 1968; Tamanaha, 2012; Moraes; Neves, 2012). Já a ocupação Paredão apresenta vestígios concentrados em densidade e em sítios arqueológicos maiores, porém numa área geográfica muito mais restrita que nas ocupações mencionadas anteriormente.

O grande centro político da ocupação Paredão parece ter se localizado nas proximidades do encontro dos rios Negro e Solimões. Nas duas margens do rio Negro, próximo de sua desembocadura, são encontradas dezenas de sítios arqueológicos associados à fase Paredão.

Nas proximidades de Manaus a fase Paredão tem contextos muito bem datados. Uma bateria de datas produzidas pelo PAC (Neves, 2010; Moraes, 2013) e datas produzidas pelo próprio Hilbert por ocasião da identificação da fase Paredão colocam-na entre os séculos V e XIII da era cristã.

No período subsequente, nos sítios com evidências de ocupações que chamamos de fase Guarita, as evidências arqueológicas são de escala muito menor.

Esse não parece ter sido um fenômeno restrito à Amazônia central, na ilha de Marajó, por volta do século IX ao XII, os grandes construtores de tesos da fase Marajoara, tidos como representantes de um dos mais complexos cacicados da Amazônia (Schaan, 2004), também entram em colapso. Evidências de áreas mais amplas da América mostram que esse período foi crítico até mesmo para as grandes civilizações do México e da América Central. Nesses casos, parece que, além dos conflitos entre diferentes cidades-Estado, as epidemias e o esgotamento dos recursos no ambiente podem ter sido causas do declínio. Lucero (2002, p.820-1) sugere que no caso Maia a instabilidade climática pode ter provocado tanto um desequilíbrio na agricultura quanto no controle dos reservatórios de água artificiais, dificultando a manutenção dos grandes centros políticos.

$\mathrm{Na}$ Amazônia central dados paleoclimáticos refinados ainda não foram produzidos. Nesse período de ocupação na Amazônia são claras as evidências de formação de centros políticos multiétnicos (Hornborg; Hill, 2011). Nossos dados apontam com segurança para evidências de guerra (Moraes; Neves, 2012), porém outros fatores devem ser considerados.

Victor Py-Daniel (comunicação pessoal, 2011), conhecido etnoepidemiólogo em atividade na Amazônia nos últimos trinta anos, chama a atenção para o fato de que os arqueólogos dão pouca importância para a ocorrência de grandes epidemias no passado da Amazônia.

Vestígios de bactérias semelhantes às da tuberculose foram encontradas 
nos Estados Unidos, em ossos de bisão, datados de dezessete mil anos (Ujvari, 2009, p.66). Vestígios da tuberculose também foram identificados em múmias Anasazi nos Estados Unidos, em múmias Huaris, Paracas, Maitas e Chiribayas na América do Sul (ibidem, p.74 e 75).

A dificuldade de preservação de restos orgânicos nos contextos arqueológicos amazônicos talvez seja uma das principais causas da quase ausência de estudos sobre paleopatologia em populações antigas da região. Porém, se levantarmos a possibilidade de epidemias pensando em evidências indiretas, algumas considerações podem ser construídas.

As grandes concentrações de pessoas em assentamentos sedentários por volta do ano mil estão presentes em várias partes da Amazônia, ilha de Marajó, alto rio Xingu, Santarém, baixo rio Madeira, nas proximidades de Manaus e vários outros pontos. $\mathrm{O}$ tamanho das áreas ocupadas e o intenso processo de formação de terra preta nos sítios desse período não deixam dúvidas quanto a isso. Heckenberger et al. (2008) e Neves (2011, p.49) falam de urbanismo na Amazônia desse período.

Pesquisadores de diversas áreas do conhecimento vêm estudando as características físicas e químicas das terras pretas da Amazônia. Apesar das divergências no tocante à intencionalidade ou não da produção dessa terra, todos concordam que a terra preta se formou principalmente com o intenso descarte de matéria orgânica em assentamentos humanos antigos da Amazônia (Woods; McCann, 1999; Glaser; Birk, 2012). Nesse sentido acreditamos que riqueza e intensa atividade microbiológica gerada durante o descarte que levou à formação da terra preta deve ser vista também como um fator preocupante para a vida sedentária urbana da Amazônia antiga.

A intensa atividade de queima de matéria orgânica também observada nos estudos da gênese da terra preta deve ser considerada não somente como um grande laboratório de produção de fertilizante, mas também, e antes de tudo, como uma estratégia de saneamento básico. Uma das melhores possibilidades de controle da proliferação de bactérias, germes e vermes no material orgânico descartado seria a queima desse material.

As redes de trocas de longa distância são vastamente documentadas nos contextos ameríndios, com as evidências arqueológicas de dispersão de complexos artefatuais semelhantes em vastas regiões. No caso das ocupações que chamamos de policromas datadas do século IX até períodos posteriores à chegada dos europeus, a padronização dos artefatos, seja do ponto de vista formal, seja do decorativo, nos faz pensar em redes de contatos numa área que vai desde o rio Madeira, no estado do Amazonas, até o rio Napo, no Equador (seguindo o curso dos rios, uma área de mais de três mil quilômetros de extensão). Evidências como essas nos fazem pensar que no período dos grandes assentamentos multiétnicos as terras baixas, e mesmo essas com as terras altas, estavam conectadas. 


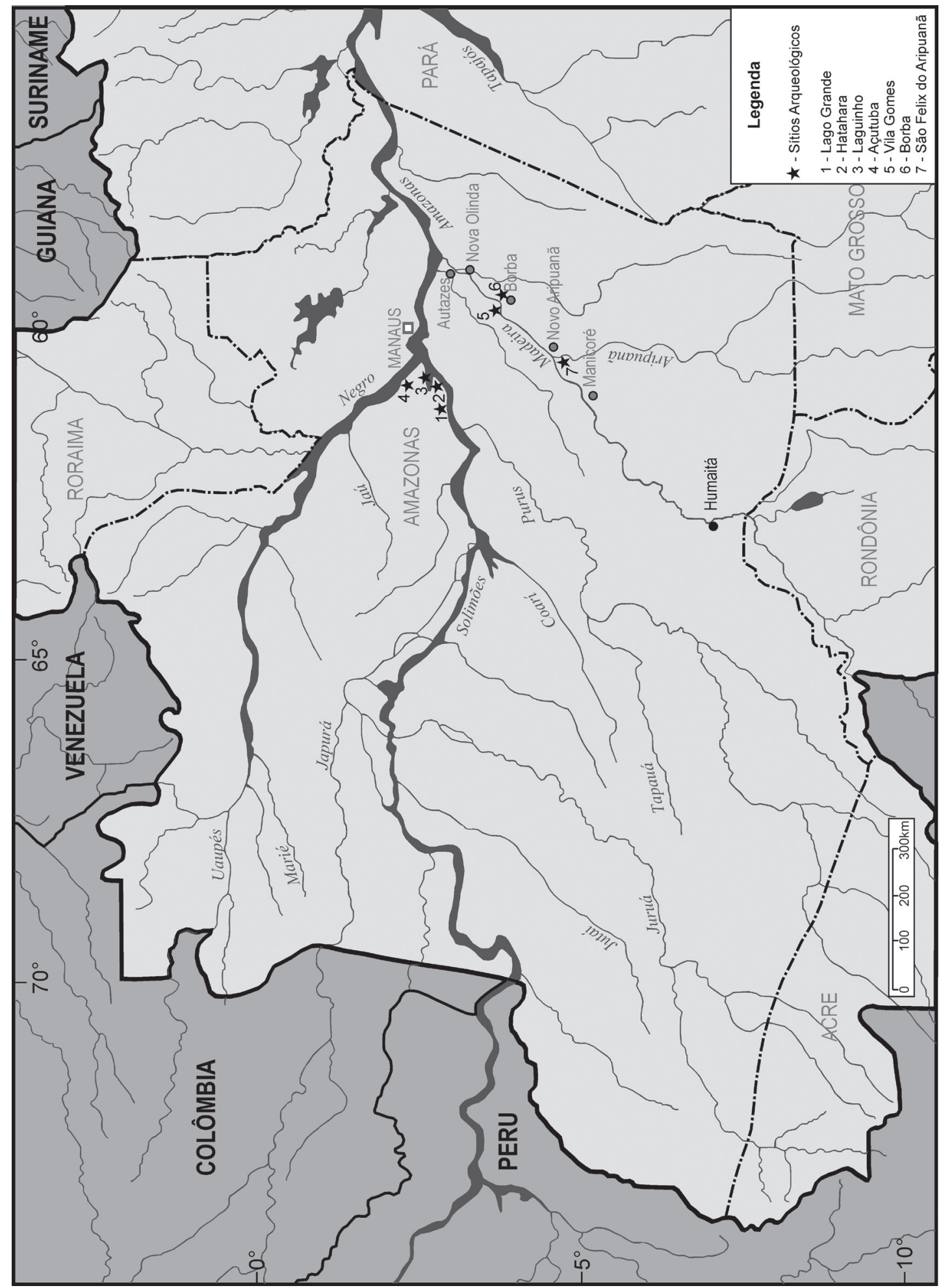

Créditos: Mapa de Marcos Brito Castro, com acréscimos do autor.

Figura 1 - Amazônia Central com os sítios arqueológicos discutidos. 
A associação de uma emergente aglomeração populacional em assentamentos permanentes e extensas redes de contato pode ter disseminado várias doenças que ainda não foram mapeadas. Por volta do ano mil várias populações já haviam domesticado animais como no caso dos camelídeos nos Andes (Stahl, 1999). O contato entre populações que estabeleceram convivência de longa duração com determinados animais e suas doenças, e outras que não o tiveram, mesmo que de forma indireta, pode ter disseminado epidemias e contribuído para a redução da população.

Diante disso, na Amazônia as possibilidades de epidemias e mesmo de uma pressão por conta de uma utilização excessiva dos recursos não podem ser descartadas como fatores do declínio populacional pré-colonial, porém pesquisas a esse respeito ainda estão por vir. Até o momento as evidências mais claras do declínio parecem relacionadas à emergência de conflitos.

Os conflitos entre populações indígenas da América do Sul têm ligação muito forte com a chegada dos europeus e a busca por minérios e mão de obra escrava a partir do século XVI (Neves, 2006, p.142 e 143). Porém, ao considerarmos o significativo papel dos europeus no desencadeamento dos conflitos pós-século XVI, não podemos desconsiderar as evidências materiais de épocas anteriores ao contato.

Ulrico Schmidl (1945, cap. XXI), um dos invasores europeus do atual território do Paraguai, descreveu em detalhe a existência de estruturas defensivas que fortificavam aldeias no século XVI.

[...] este pueblo antes se llamó, en lengua de los indios, Lambore la ciudad de ellos está rodeada con 2 pallersaide de madera, cada poste del grueso de un hombre; e la una pellersaide está a 12 pasos de la otra; los postes están encerrados o clavados en honduras de 6 pies, y se levantan del suelo que puede alcanzar un hombre con la punta de su tizona.

No período das grandes chefias regionais da Amazônia os diferentes grupos parecem ter alternado momentos de paz e aliança com momentos de tensão e guerras (Neves; Petersen, 2006). Essa alternância pode ser observada se considerarmos os dados dos cronistas dos séculos XVI e XVII sintetizados por Porro (1996). A calha do Amazonas foi a única região na Amazônia onde essas chefias regionais foram documentadas pelos colonizadores europeus (Carvajal, 1942; Porro, 1996; Ugarte, 2009). Eles mencionaram vastas províncias como a de Aparia o Grande (Carvajal, 1942, p.15), provavelmente a província dos Omagua (Porro, 1996, p.48).

Além das chefias regionais os cronistas coletaram informações sobre alianças entre chefes para combater inimigos comuns. Por exemplo, Aparia e seus confederados supostamente estavam em constante conflito com seus vizinhos a jusante do rio, os Aisuari da província de Machifaro (Porro, 1996, p.80). A demarcação das províncias descritas pelos cronistas e a mudança das fronteiras dos territórios entre os séculos XVI e XVII demonstram a fluidez 
dos sistemas políticos regionais indígenas do passado na Amazônia Central (Porro, 1996).

Na transcrição de Medina, no relato de Carvajal (1942, p.39), é mencionada, logo abaixo da passagem pelo rio Negro, a existência de povoações muito grandes e uma delas fortificada com uma muralha de madeiras muito grossas. No final do século XVII Betendorf (apud Nimuendajú, 2004, p.167) menciona a existência de aldeias fortificadas entre os índios Arawakí do rio Urubu, no baixo Amazonas. Alfred Métraux (1942, p.63) documenta estruturas semelhantes nas aldeias dos índios Baure na Bolívia. "Baure villages were surrounded by palisades with loopholes for archers, and a ditch; for further protection pitfalls were concealed in the paths".

Arqueólogos trabalhando na Amazônia nas últimas décadas divergiram muito sobre a comparação do registro arqueológico em contraste com os dados mencionados pelos primeiros cronistas (Carneiro, 2007). Após a constatação da evidência de extensas áreas com depósitos arqueológicos que poderiam ser associadas a grandes adensamentos populacionais semelhantes aos descritos pelos cronistas, como é o caso do sítio Aldeia na área urbana de Santarém, no encontro dos rios Tapajós e Amazonas (Nimuendajú, 2004), os contestadores da possibilidade de um número muito maior de humanos ocupando a Amazônia no período pré-colonial argumentaram que os grandes sítios arqueológicos seriam o resultado da acumulação de refugos de sucessivas pequenas ocupações de curta duração que ao longo do tempo se sobrepuseram ou foram se associando adjacentes às mais antigas ao ponto de formar grandes sítios arqueológicos (Meggers, 1990).

De fato, grande parte dos sítios arqueológicos da Amazônia são multicomponenciais, porém as pesquisas recentes vêm mostrando que em quase todos os casos, mesmo em sítios com múltiplas ocupações, uma delas é responsável pela total espacialidade do sítio (Moraes; Neves, 2012).

Heckenberger $(2005$, p.118), em seu trabalho no alto Xingu, demonstrou que as ocupações antigas dos ancestrais dos Kuikuru deixaram vestígios em áreas delimitadas por valas defensivas em espaços muito maiores que as atuais aldeias da região.

Na bacia do rio Madeira, no município de Borba, o sítio Vila Gomes figura como um bom exemplo que pode contestar a associação de extensos depósitos de refugo arqueológico a múltiplas ocupações. Como no exemplo do Xingu, o sítio Vila Gomes, que apresenta grandes proporções territoriais, tem cerca de vinte hectares de área delimitados por uma vala defensiva. Hoje podemos afirmar com segurança que existiram grandes assentamentos na Amazônia antiga. Portanto, o registro arqueológico identificado nas pesquisas mais recentes corrobora os dados históricos.

Evidências de conflitos na virada do primeiro para o segundo milênios d.C. puderam ser confirmadas por meio da escavação de estruturas defensi- 
vas em sítios das ocupações Paredão e nas ocupações Axinim (Moraes; Neves, 2012). Tais estruturas podem ser valas defensivas, como as encontradas nos sítios Lago Grande (Neves, 2005, 2008; Donatti, 2003), Açutuba (Neves, 2008), Vila Gomes e Borba (Moraes, 2010), ou então paliçadas, como no caso do sítio Laguinho (Castro, 2009; Tamanaha, 2012).

No sítio Lago Grande, localizado em uma península com mais de trinta metros de altura sobre um lago da várzea do rio Solimões, uma vala artificial foi construída no istmo que conecta a península à terra firme no início do século XI d.C., mais de dois séculos após o início da ocupação do sítio. Pouco tempo depois, o sítio foi abandonado (Neves, 2008). No sítio Açutuba, também localizado em um barranco com mais de trinta metros de altura, mas dessa vez em relação à planície aluvial do rio Negro, uma vala artificial com mais de 150 metros de extensão foi também escavada na parte do sítio acessível pela terra firme (Neves, 2008).

No sítio Laguinho, uma paliçada de mais de quarenta metros de comprimento, atestada por uma série de manchas alinhadas de buracos de poste, foi construída em uma península que separa a parte central do sítio - uma vez mais localizada sobre um barranco alto adjacente à várzea do rio Solimões - da área acessível pela terra firme (Tamanaha, 2012).

Na região do rio Madeira a emergência de conflitos leva a uma reconfiguração do espaço ocupado no sítio Vila Gomes. Por volta do ano mil a construção da vala delimita uma área de vinte hectares. Como apontam os dados, esse é o período da expansão da ocupação Guarita. As evidências de sistemas defensivos de outros sítios como Lago Grande, Açutuba e Laguinho (Moraes; Neves, 2012) também estão associadas ao início do aparecimento de ocupações policromas na área.

As valas defensivas identificadas no alto Xingu também apresentam datas próximas ao início do segundo milênio da era cristã (Heckenberger, 2005, p.121).

\section{Quais seriam então as causas do conflito?}

No modelo tradicional de interpretação do período pré-colonial da Amazônia o conceito de cultura de floresta tropical cunhado pelos editores do Handbook of South American Indians (Steward, 1948) foi explicado pela dicotomia entre as áreas de várzea e a terra firme. O modelo degeneracionista de Meggers (1971) sugeriu que populações de complexidade social mais elevada que as de floresta tropical teriam se aventurado pela Amazônia e em razão das limitações impostas pelo ambiente teriam encontrado nas áreas de várzea uma possibilidade de desenvolver agricultura e permanecer por mais algum tempo com seu padrão cultural externo à Amazônia, porém a imprevisibilidade da várzea teria inevitavelmente levado essas populações a decair para o nível de floresta tropical.

O modelo colocou como prerrogativa essencial para o desenvolvimento de algum tipo de complexidade socioeconômica a existência de agricultura. Um 
dos fatores que poderiam então desencadear os conflitos evidenciados por volta do ano mil seria a disputa pelos escassos solos agricultáveis da várzea amazônica ou mesmo pelas extensas áreas de terra preta previamente formadas.

Os arqueólogos trabalhando na Amazônia, no entanto, vêm cada vez mais demonstrando o papel secundário da agricultura entre as populações Amazônicas do passado. Ironicamente a sociedade Marajoara tida como o indiscutível exemplo amazônico de sociedade hierarquizada complexa (Meggers; Evans, 1957; Roosevelt, 1991; Schaan, 2004) parece ser um dos contextos arqueológicos onde menos sinais de práticas agrícolas foram evidenciados. Como destacou Carneiro (1995, p.54), o milho apontado como a base dos cacicados amazônicos, segundo as pesquisas de Anna Roosevelt, não aparece na sua publicação de 1991 sobre o cacicado de Marajó.

Recentemente Eduardo Neves vem colocando essa questão à prova mostrando que mesmo desconsiderando a presença do milho como importante para o estabelecimento de sedentarismo e complexidade social, a própria mandioca, domesticada há milhares de anos nas terras baixas, parece ter tido importância reduzida na dieta das populações do passado (Neves, 2012, p.276).

De fato, uma observação cuidadosa dos relatos dos cronistas mostra que o provimento que eles conseguiram junto aos indígenas durante suas jornadas pela Amazônia era principalmente de pescado, quelônios, mamíferos e aves. No relato do frei Gaspar de Carvajal, o mais antigo acerca dos indígenas da Amazônia, transcrito por Toribio Medina, é possível encontrar cerca de treze trechos mencionando a variedade de suprimentos conseguidos pela tropa de Orellana mediante saques ou doações nas aldeias indignas (Carvajal, 1942, p.11, 16, 17, $24,27,28,39,41,45,47,57$ e 70$)$. Quatro das menções estão relacionadas a provisões de milho, uma delas deixando dúvida quanto à veracidade, pois junto com o milho também é mencionada a presença de aveia. A menção do provimento de milho é mais frequente no baixo Amazonas, justamente onde o relato parece mais fantasioso. Todas as outras informações são acerca de muita provisão de tartarugas, pescados e aves. São mencionados currais para armazenar quelônios vivos, processo de secagem de peixe para estoque e comércio, mostrando claramente a importância da caça, pesca e coleta no cotidiano destas populações:

[...] com muy gran brevidad trajeron abundantemente lo que fué necessário asi de carnes, pedices, pavas y pescado de muchas maneras. [...] comenzaron a sacar de sus canoas muchas perdices como las de nuestra España, sino que son mayores, y muchas tortugas, que son tan grandes como adárgas, y otros pescados. (Carvajal, 1942, p.11 e 16)

Aqui se halló mucho maiz (y assimismo se halló mucha avena) de lo que los indios hacem pan, y muy buen vino a manera de cerveza. (ibidem, p.47)

Os deterministas ambientais construíram todo um discurso para mostrar que a ausência de agricultura proporcionada pela imposição dos solos pobres 
da Amazônia seria o fator limitante para o desenvolvimento cultural na área de floresta tropical (Meggers, 1971). Parece que esse argumento colocou a grande maioria dos arqueólogos posteriores na armadilha da procura dos sinais de agricultura como contraprova. Mesmo não aceitando o determinismo ambiental aceitamos o "determinismo agrícola" como marcador de complexidade social. Roosevelt (1991) e sua procura pelos plantadores de milho parece ser um dos exemplos mais clássicos desse processo. Donald Lathrap construiu todo seu modelo de expansões linguísticas em função da busca de terrenos aluviais propícios para o cultivo (Lathrap, 1970, p.68-83).

Como demonstrou Neves (2012, p.175), o surgimento das terras pretas e a grande fertilidade comprovada nesses solos sepultou de vez o determinismo ecológico como fator limitante para a ocupação humana na Amazônia. A terra preta trouxe de volta a possibilidade de fazer agricultura e se desenvolver sem barreiras pela Amazônia. Curiosamente, como bem aponta Neves (2012, p.275), parece que mesmo conhecedores das terras pretas e de sua fertilidade, os amazônicos do passado a "desperdiçaram", utilizando-as para a construção de montículos no sítio Laguinho (Castro, 2009) e no sítio Hatahara (Neves et al., 2004; Machado, 2005; Rapp Py-Daniel, 2009). Na maioria dos casos as áreas de terras pretas e principalmente as partes onde as camadas são mais profundas estão em áreas de habitação (Neves, 2012). Vila Gomes e Antônio Galo são exemplos clássicos desse fenômeno. Como dito anteriormente, questões relacionadas ao saneamento básico precisam ser também consideradas no processo de formação da terra preta, uma vez que é no espaço doméstico que ela está se formado.

Um fator interessante de incluir na discussão são as evidências de conflitos apresentadas anteriormente. Alguns autores já associaram a emergência de conflitos à disputa de locais com extensas áreas de terras pretas ou mesmo o controle das ricas várzeas amazônicas (Rebellato; Woods, 2012, p.446). Os pontos apresentados anteriormente parecem não corroborar essa hipótese.

Outro fator importante é que, caso os povos amazônicos antigos fossem detentores da fórmula de produção de terra preta em larga escala, não teriam dificuldades em se estabelecer em locais mais distantes das várzeas amazônicas e produzir alimentos agrícolas em abundância. Até o momento os trabalhos arqueológicos na Amazônia vêm identificando sítios com terras pretas em lugares muito remotos, porém nenhum deles com as proporções dos grandes sítios das margens dos rios. Por que então a várzea é o palco dos conflitos?

\section{A luta foi pelo Rio e não pela Várzea}

Recomendamos orientarem, de início, as pesquisas de sítios e cortes-experimentais às áreas junto às cachoeiras, corredeiras e baixios dos rios, que nas estiagens propiciavam grandes pescarias pré-históricas. Ai estão os sítios principais [...] (Miller, 2009, p.107)

Conforme aponta Miller (2009), praticamente todas as imediações de cachoeiras e corredeiras de rio da Amazônia foram locais de ocupação humana 
desde períodos muito antigos. Na cachoeira Teotônio, no rio Madeira, Miller encontrou ocupações que recuam a cerca de cinco mil anos. O mesmo pôde ser documentado na cachoeira de Samuel no rio Jamari (Miller, 1992), nas cachoeiras da Sumaúma e dos Patos (Valle; Moraes, 2007), rio Aripuanã, e em vários pontos da Amazônia existe relação entre sítios arqueológicos e acidentes geográficos.

Com o passar do tempo, e as constantes ocupações, a paisagem desses lugares foi humanizada e sacralizada, transformando-se em partes de mitos de origem de vários povos amazônicos. No caso dos povos Tukano da bacia do rio Negro, Stephen Hugh-Jones (1995, p.235) mostra que na concepção de criação, na definição da vida social, na localização das aldeias (míticas e/ou físicas), e da espacialidade da casa, o rio e seus acidentes geográficos estão todos mapeados:

The anaconda's journey gave rise to the river and its stopping places, the rapids and rock outcrops along the river, are "transformation houses" sacred sites and ancestral dwellings created by the dance of the feather-people.

Ainda na bacia do rio Negro, Raoni Valle (2012) mostra que esses lugares frequentemente coincidem com vasta representação simbólica, sendo locais preferenciais para as gravuras rupestres.

Ao que tudo indica, o rio e não a várzea foi o motivo da disputa e da emergência de conflitos. Analisando o contexto arqueológico em escala amazônica nosso argumento parece mais plausível. Nesse processo de humanização da paisagem parece que os encontros de grandes rios foram também locais preferenciais para a ocupação humana; pelo menos nos dois últimos milênios, vários dos sítios desses locais parecem ter sido permanentemente ocupados.

Do ponto de vista da exploração dos recursos essas áreas apresentam concentração de fauna aquática endêmicas dos diferentes sistemas hídricos amazônicos, águas pretas, águas claras e águas brancas (Lucia Rapp Py-Daniel, comunicação pessoal, 2013). Do baixo para o alto Amazonas temos as evidências arqueológicas de maiores concentrações de pessoas primeiramente na ilha de Marajó. Na foz do rio Xingu, na vila de Gurupá, Glenn Shepard Jr. (2012) documentou um grande sítio de terra preta. Na foz do rio Tapajós, na atual área urbana de Santarém, está o que talvez seja um dos maiores sítios arqueológicos da Amazônia, o sítio Aldeia, associado à cultura Tapajônica (Nimuendajú, 2004; Roosevelt, 1992; Gomes, 2002). Nas proximidades de Óbidos, na foz do rio Trombetas, existem extensas áreas de terras pretas associadas a sítios com cerâmicas Konduri. No rio Madeira em nossa área de pesquisa, nas proximidades da foz do rio Aripuanã, está o sítio São Felix do Aripuanã (Figura 1), o maior encontrado no levantamento arqueológico que realizamos na área, tendo sua extensão estimada em oitenta hectares. $\mathrm{Na}$ foz do rio Negro, no município de Iranduba, está o sítio Açutuba com noventa hectares de área (Heckenberger et al., 1998; Lima, 2008). 
Todos os exemplos listados apresentam pontos em comum, são sítios arqueológicos de proporções muito grandes e em áreas de diversidade ambiental, no caso da ilha de Marajó, o encontro do rio Amazonas com o mar e nos outros exemplos o encontro de rios de águas claras e águas pretas com rios de água branca como o rio Amazonas e o rio Madeira.

Portanto, a agricultura com a adição de terra preta poderia ser levada para qualquer ponto da Amazônia, mas a disponibilidade de recursos de fauna aquática não. No nosso entendimento, esse padrão nos sítios arqueológicos amazônicos seria uma evidência forte do papel secundário da agricultura nas ocupações do passado. Esse argumento não é novo, nos anos 1980 Robert Carneiro (2007), em suas pesquisas no alto rio Xingu e em trabalhos de discussões mais amplas sobre a vida nas terras baixas, propõe que o cultivo de mandioca e a exploração dos recursos faunísticos aquáticos seriam a base dos cacicados amazônicos. Em várias passagens do texto de Carneiro são mencionadas evidências dos relatos históricos de que peixes, mamíferos e quelônios seriam estocados e comercializados entre os habitantes da várzea e da terra firme. Mesmo Carneiro chegando muito próximo de nosso argumento, em sua discussão da dicotomia entre várzea e terra firme a agricultura surge novamente como fator principal para as disputas territoriais:

A outra desvantagem da várzea, que vou examinar agora, é sua escassez. Desde que, em adição a ser louvada, a várzea é também limitada quanto à sua ocorrência, uma vez que as populações amazônicas tinham crescido a um certo tamanho, a várzea veio a faltar. $\mathrm{E}$ não havendo em quantidade suficiente, a competição em torno dela iniciou-se. (Carneiro, 2007, p.144)

Se causado por um aumento de pessoas ou uma diminuição de terras, uma vez que a oferta de terra arável cai abaixo da demanda, o palco está armado para uma aquisição forçada, pela expropriação de seus vizinhos. (ibidem, p.145)

Mas como anteriormente apontamos, parece que o determinismo agrícola desviou bastante a atenção dos pesquisadores nos últimos tempos.

\section{É melhor caçar e pescar ou retirar ervas daninhas de uma plantação?}

Sobre a dieta das populações indígenas às margens do rio Amazonas Critóbal de Acunã diz o seguinte:

[...] do que mais se alimentam, ou, como dizem, lhes faz o prato, é de peixe, incrivelmente abundante neste rio, onde o pescam a mancheiras. Porém, dentre todos os pescados, aquele que, como um rei, se assenhoreia do das Amazonas, o enche todo, desde seu começo até quando deságua no mar, é o peixe-boi, que pelo saber já justifica o nome, pois não há quem o coma que não o tenha por boa carne. (Acunã, 1994, p.78)

O pescado é ainda hoje parte importante da dieta na Amazônia. No ano 1979 a estimativa é de que só nos portos de Manaus foram desembarcadas 
32.270 toneladas de peixes (Castelo, 1992, p.464). Em 2009 o número é de cerca de 27 mil toneladas (Granda, 2010). Considerando só o pirarucu (Arapaima gigas) que ainda é pescado de maneira artesanal, entre os anos 1950 e 1960, a estimativa é de que a pesca anual chegou 4,7 mil toneladas (Bessa; Lima, 2010, p.2). Numa tentativa de imaginar um retrato do passado teríamos que acrescentar a essa disponibilidade de recursos algumas centenas de milhares de peixes-boi e quelônios, hoje já bastante escassos na Amazônia. Sobre as tartarugas, Acunã (1994, p.81-1) diz o seguinte:

Os índios apanham as tartarugas em tão grande quantidade, que não há viveiro delas que não tenha de cem para cima, motivo pelo qual esses bárbaros nunca souberam o que seja fome, pois basta uma delas para satisfazer uma família, por numerosa que seja.

A pescaria hoje em dia virou esporte e atividade de lazer. O cuidado com a roça é atividade laboriosa e desgastante. Charles Clement et al. (2012), discutindo a história da agricultura no mundo, faz uma analogia interessante sobre a diversidade de pontos de vista do homem sobre o assunto no decorrer do tempo. Clement et al. (2012, p.4), citando Harlan, mostra que as sociedades agrícolas se amparam em mitos para convencer os responsáveis pelas atividades agrícolas que mesmo elas sendo mais laboriosas que a caça e a coleta elas dignificam o homem. Os mitos geralmente mostram que os agricultores são mais inteligentes e civilizados que os bárbaros que vivem da caça e coleta. Segundo Clement $(2012$, p.4), uma forma de olhar para esses mitos é que servem para "lavagem cerebral" para convencer os próprios produtores que seu esforço vale a pena, mesmo que precisem trabalhar muito mais do que os caçadores-coletores para seu sustento.

Clement mostra que mesmo na visão cristã, em que a necessidade de produzir o próprio alimento é tida como um castigo pelo pecado cometido por Adão e a consequente expulsão do paraíso, não resta muita opção ao agricultor senão aceitar o ônus do pecado.

Em certa medida parece que ainda somos vítimas desses mitos que nos levam em busca das evidências da agricultura no pacote civilizatório do homem.

Levando a questão para a cerâmica, um dos principais vestígios arqueológicos do passado amazônico, parece que novamente a caça e a pesca exercem um papel mais importante. Praticamente não existem representações naturalistas de plantas na decoração da cerâmica amazônica. Por outro lado, pássaros, mamíferos, anfíbios, peixes e quelônios são abundantemente representados.

Pelo que demonstram as narrativas sobre povos ameríndios ou mesmo em nossas experiências no meio rural atual da Amazônia, um indivíduo adquire status diferenciado dentro do grupo principalmente por suas habilidades como caçador ou pescador. É possível observar elogios para um indivíduo bom de pontaria ou bom pescador, mas não parece ser um marco diferencial tão significativo o fato de um indivíduo conseguir derrubar rapidamente a capoeira de uma grande área de roça ou ser habilidoso para cuidar das ervas daninhas. 


\section{O coletor}

Quem já esteve em um porto de carga na Amazônia e presenciou a chegada de um carregamento de pupunha, açaí ou castanha sabe que não é preciso cultivar grandes campos para se obter alimento na Região Amazônica. Na cidade de Óbidos, no estado do Pará, na safra da castanha, é possível passar horas observando o carregamento de balsas com milhares de sacas vindas da bacia do rio Trombetas.

No ano 2000, o Brasil produziu 33.431 toneladas de castanha (Bertholletia excelsa) (Salomão et al., 2006, p.76). De acordo com informações da Embrapa (Nogueira, 2006), só no estado do Pará são produzidas anualmente 160 mil toneladas de açaí (Euterpe oleracea). Uma touceira pode produzir até 120 quilos anuais de açaí (Cymerys; Shanley, 2005, p.164). Do açaí ainda pode ser aproveitado o palmito como fonte de alimento. Uma única palmeira de pupunha (Bractris gasipaes) pode produzir anualmente de 10 a 120 quilos de frutos (Cymerys; Clement, 2005, p.210). Vários frutos como buriti (Mauritia flexuosa), bacaba (Oenocarpus bacaba), inajá (Maximiliana maripa), tucumã (Astrocaryum tucuma), piquiá (Caryocar villosum), cupuaçu (Theobroma grandiflorum), uxi (Endopleura uchi), entre outros, podem ser acrescentados à lista, mostrando o grande potencial de coleta proporcionado pelo manejo de plantas na Amazônia.

Nos exemplos mencionados estamos falando de plantas que necessitam de um manejo muito menos laborioso que o cultivo de um campo agrícola. É preciso apenas favorecer o crescimento dessas plantas para que elas produzam durante gerações.

Em um estudo de análise de microvestígios de plantas, fitólitos e grãos de amido, desenvolvido por Leandro Cascon no sítio Hatahara, apesar de terem sido encontradas evidências de milho, as principais constatações do autor são de uma diversidade muito grande de restos botânicos, principalmente de palmeiras, demonstrando uma dieta diversificada com muitos itens tradicionalmente adquiridos por coleta (Cascon, 2010, p.149). Outro trabalho em andamento no sítio Hatahara, desenvolvido por Tiago Hermenegildo, dessa vez com isótopos de carbono e nitrogênio em restos faunísticos e humanos, vem mostrando que, mesmo presente no registro arqueológico, provavelmente o milho não foi parte muito significativa da dieta das populações que ali se estabeleceram (Hermenegildo, comunicação pessoal, 2013).

Mesmo não tendo muitas evidências de agricultura em áreas de terra preta em sítios arqueológicos como demonstra Neves (2012), se tomarmos como parâmetro comparativo o modelo atual da agricultura do ribeirinho amazônico, o cultivo em áreas de terra preta fica principalmente restrito a plantas exógenas como os cítricos e a banana. Quando indagados sobre a produtividades dos cultivares dentro ou fora de áreas de terra preta os agricultores são unânimes em afirmar a maior produtividade na terra preta. Porém, na linguagem popular regional todos são também unânimes em afirmar que na terra preta "serra" muito 
mais. Serrar é a invasão das ervas daninhas, muito mais frequente na terra preta. Nicholas Kawa (2011), em suas pesquisas com agricultores do rio Madeira, constatou que em alguns casos a relação custo-benefício da produção na terra preta não é compensada pela maior necessidade de controle das ervas daninhas.

No passado o acúmulo de terra preta nas proximidades de áreas domésticas certamente favoreceu os variados cultivos de frutas, plantas medicinais e plantas mágicas, padrão que inclusive ainda pode ser observado nas comunidades amazônicas em área de terra preta. Porém, parece que ao contrário do modelo determinista de escassez que previu que o inferno verde teria levado o homem à decadência (Meggers, 1971), a abundância de recursos disponíveis na Amazônia liberou as populações do castigo da laboriosa agricultura.

\section{Considerações finais}

Os estudos arqueológicos mais recentes vêm demonstrando que as populações da Amazônia anteriores à chegada dos europeus experimentaram uma forma de uso e exploração de recursos ambientais bastante diferente do modo de vida agricultor ocidental do Velho Mundo e mesmo de regiões próximas da Amazônia como os altiplanos dos Andes.

A importância do modo de vida agrícola, da monocultura, no mundo contemporâneo parece ter levado um grande número de pesquisadores a pensar nela como possibilidade incondicional para o desenvolvimento de urbanismo, complexidade sociopolítica e manutenção de grandes contingentes populacionais.

O que estamos observando nos últimos anos é que o registro arqueológico da Amazônia nos leva a crer em um cenário bastante distinto. As populações antigas se estabeleceram, cresceram e entraram em conflito por conta de pontos estratégicos do ambiente amazônico no tocante aos recursos faunísticos e à possibilidade de exploração de um diversificado universo de plantas que também resulta de um manejo milenar que modelou a paisagem amazônica.

\section{Referências}

ACUNÃ, C. Novo descobrimento do grande rio das Amazonas - 1641. Rio de Janeiro: Agir, 1994.

BESSA, J. D. O.; LIMA, A. C. Manejo de pesca do pirarucu (Arapaima gigas) no Estado do Amazonas: erros, acertos e perspectivas futuras. In: Anais do I Seminário Internacional de Ciências do Ambiente e Sustentabilidade na Amazônia. UFAM, 2-9, 2010. CARNEIRO, R. L. The history of ecological interpretations of Amazonia: Does Roosevelt have it right. In: ESPONSEL, L. E. Indigenous peoples and the future of Amazonia: an ecological anthropology of an endangered world. Chicago: University of Arizona Press, 1995. p.45-70.

2007.

A base ecológica dos cacicados amazônicos. Revista de Arqueologia, v.20, n.1, 
CARVAJAL, G. Relación del nuevo descubrimiento del famoso Rio Grande que descubrió por muy gran ventura el capitán Francisco de Orellana. Traduzido por Oviedo e Medina e por Raul Reyes y Reyes. Quito: Biblioteca Amazonas I, 1542 [1942].

CASCON, L. M. Alimentação na Floresta Tropical: um estudo de caso no sítio Hatahara. 2010. Dissertação (Mestrado em Arqueologia) - Museu Nacional, Universidade Federal do Rio de Janeiro. Rio de Janeiro, 2010.

CASTELO, F. P. Aproveitamento racional do pescado de água doce na Amazônia. Acta Amazonica, v.22, n.3, p.449-60, 1992.

CASTRO, M. W. A cronologia dos sitios Lago do Iranduba e Laguinho à luz das hipóteses da Ocupação Humana para a Amazônia Central. 2009. Dissertação (Mestrado) - Museu de Arqueologia e Etnologia, Universidade de São Paulo. São Paulo, 2009.

CLEMENT, C. et al. A origem e a domesticação das plantas cultivadas. In: Apostila preparada para o Curso de Graduação em Arqueologia da UEA-AM. (não publicado), 2012.

CYMERYS, M.; CLEMENT, C. Pupunha (Bactris gasipaes Kunth). In: SHANLEY, P.; MEDINA, G. (Org.) Frutíferas e plantas úteis na vida amazônica. S. 1.: Cifor, 2005. p.203-8.

CYMERYS, M.; SHANLEY, P. Açaí (Euterpe oleracea Mart). In: SHANLEY, P.; MEDINA, G. (Org.) Frutiferas e plantas úteis na vida amazônica. S. 1.: Cifor, 2005. p.16370 .

DONATTI, P. B. A Ocupação Pré-Colonial da área do lago Grande, Iranduba, Amazonas. 2003. Dissertação (Mestrado) - Museu de Arqueologia e Etnologia, Universidade de São Paulo. São Paulo, 2003.

EVANS, C.; MEGGERS, B. Archaeological Investigation on the Rio Napo, Eastern Ecuador. Smithsonian Contributions to Anthropology 6. Washington, D. C.: Smithsonian Institution, 1968.

GLASER, B. et al. The "Terra Preta” phenomenon: a model for sustainable agriculture in the humid tropics. Naturwissenschaften, v.88, n.1, p.37-41, 2001.

GLASER, B.; BIRK, J. J. State of the scientific knowledge on properties and genesis of Anthropogenic Dark Earths in Central Amazonia ("terra preta de Índio"). Geochimica et Cosmochimica Acta, v.82, p.39-51, 2012.

GOMES, D. M. C. Cerâmica Arqueológica da Amazônia: vasilhas da coleção Tapajônica da Amazônia MAE-USP. São Paulo: Edusp; Imprensa Oficial, 2002.

GRANDRA, A. L. O mercado de pescado da Região Metropolitana de Manaus. Montevideo: Infopesca, 2010.

GUAPINDAIA, V. L. Além da margem do rio: as ocupações Konduri e Pocó na região de Porto Trombetas, PA. 2008. Tese (Doutorado) - Museu de Arqueologia e Etnologia, Universidade de São Paulo. São Paulo, 2008.

HECKENBERGER, M. J. The ecology of power: culture, place, and personhood in the Southern Amazon, A.D. 1000-2000. New York: Routledge, 2005.

HECKENBERGER, M. J. et al. De onde surgem os modelos?: Considerações sobre a origem e expansão dos Tupi. Revista de Antropologia, v.41, p.69-96, 1998. 
HECKENBERGER, M. et al. Pre-Columbian urbanism, anthropogenic landscapes, and the future of the Amazon. Science, v.321, n.5893, p.1214-17, 2008.

HILBERT, P. P. Archäologische Untersuchungen am mittleren Amazonas: Beiträge zur Vorgeschichte des südamerikanischen Tieflandes. Mit 164 Abbildungen und 11 Karten (vom Verfasser). Berlin: Marburger Studien zur Völkerkunde; Bd. 1. Reimer, 1968.

HORNBORG, A.; HILL, J. D. Ethnicity in Ancient Amazonia: reconstructing past identities from archaeology, linguistics, and ethnohistory. Colorado: University Press of Colorado, 2011.

KAWA, N. C. The Social Nature of Agrobiodiversity in Central Amazonia. 2011. Tese (Doutorado) - University of Florida. Gainesville, 2011.

LATHRAP, D. W. The Upper Amazon. Ancient peoples and places. Southampton: Thames \& Hudson, 1970.

LIMA, H. P. História das Caretas: a tradição Borda Incisa na Amazônia Central. 2008. Tese (Doutorado) - Museu de Arqueologia e Etnologia, Universidade de São Paulo. São Paulo, 2008.

LUCERO, L. J. The collapse of the Classic Maya: A case for the role of water control. American Anthropologist, v.104, n.3, p.814-26, 2002.

MACHADO, J. S. Montículos artificiais na Amazônia Central: um estudo de caso do sítio Hatahara. 2005. Dissertação (Mestrado) - Museu de Arqueologia e Etnologia, Universidade de São Paulo. São Paulo, 2005.

MEGGERS, B. J. The native tribes of eastern Bolivia and western Mato Grosso. Bureau of American Ethnology Bulletin, v.134, p.1-182, 1942. ton, 1971 .

Amazonia: Man and culture in a counterfeit paradise. Chicago: Aldine; Ather-

. Reconstrução do comportamento locacional pré-histórico na Amazônia. Boletim do Musen Paraense Emilio Goeldi: Série Anthropologia, Belém, v.6, n.2, p.183-203, 1990.

MEGGERS, B. J.; EVANS, C. Archeological investigations at the mouth of the Amazon. Washington, D.C.: U.S.G.P.O, 1957.

MÉTRAUX, A. The native tribes of eastern Bolivia and western Matto Grosso. Bureau of American Ethnology Bulletin, v.134, p.1-182, 1942.

MILLER, E. T. Arqueologia nos empreendimentos hidroelétricos da Eletronorte: resultados preliminares. Brasília: Eletronorte, 1992.

A cultura cerâmica do tronco Tupi no alto Ji-Paraná, Rondônia, Brasil: algumas reflexões teóricas, hipotéticas e conclusivas. Revista Brasileira de Linguistica Antropológica, v.1, n.1, p.35-136, 2009.

MORAES, C. de P. Aldeias circulares na Amazônia Central: um contraste entre fase Paredão e fase Guarita. In: PEREIRA, E.; GUAPINDAIA, V. (Ed.) Arqueologia Amazônica v.2. Belém: MPEG; Iphan; Secult, 2010. p.581-604.

Amazônia ano 1000: Territorialidade, interação e conflito no tempo das chefias regionais. 2013. Tese (Doutorado) - Museu de Arqueologia e Etnologia, Universidade de São Paulo. São Paulo, 2013.

MORAES, C. de P.; NEVES, E. G. O ano 1000: adensamento populacional, interação 
e conflito na Amazônia Central. Amazônica-Revista de Antropologia, v.4, n.1, p.122-48, 2012 .

NES, S. Inside-out and back-to-front: the Androgynous house in northwest Amazonia. In: CARSTEN, J.; HUGH-JONES, S. (Ed.). About the House: Lévi-Strauss and Beyond. Cambridge: Cambridge University Press, 1995. p.226-52.

NEVES, E. G. Warfare in Precolonial Amazonia: when Carneiro meets Clastres. In: NIELSEN, A.; WALKER, W. (Ed.) Warfare in cultural context: practice theory and the archaeology of war. Tucson: University of Arizona Press, 2005.

Arqueologia Amazônica. Rio de Janeiro: Jorge Zahar Editora, 2006.

Ecology, ceramic chronology and distribution, long-term History, and political change in the Amazonian Floodplain. In: SILVERMAN, H.; ISBELL, W. (Ed.) Handbook of South American Archaeology. New York: Springer, 2008. p.359-79.

Arqueologia da Amazônia Central e as classificações na Arqueologia Amazônica. In: PEREIRA, E.; GUAPINDAIA, V. (Ed.) Arqueologia Amazônica v.2. Belém: MPEG; Iphan; Secult, 2010. p.561-79.

Archaeological cultures and past identities in Precolonial Central Amazon. In: HORNBORG, A.; HILL, J. (Org.) Ethnicity in Ancient Amazonia: reconstructing past identities from archaeology, linguistics, and ethnohistory. Boulder: University of Colorado Press, 2011. p.31-56.

Sob os tempos do Equinócio: oito mil anos de História na Amazônia Central (6.500 AC - 1.500 DC). 2012. Tese (Livre-Docência) - Museu de Arqueologia e Etnologia, Universidade de São Paulo. São Paulo, 2012.

NEVES E. G.; PETERSEN J. B. Political economy and pre-Columbian landscape transformations in Central Amazonia. In: BALÉE, W.; CLARK L. E. Time and complexity in Historical Ecology: studies in the Neotropical Lowlands. New York: Columbia University Press, 2006. p.279-309.

NEVES, E. G. et al. The timing of terra preta formation in the central Amazon: Archaeological data from three sites. In: GLASER, B.; WOODS, W. I. (Ed.) Amazonian dark earths: Explorations in space and time. Berlin: Springer Verlag, 2004. p.125-34.

NIMUENDAJÚ, C. In pursuit of a past Amazon - Archaeological researches in the Brazilian Guyana and in the Amazon Region. Transl. S. Rydén and P. Stenborg. Göteborg: s. n., 2004.

NOGUEIRA, O. L. Sistema de produção do açaí. Embrapa Amazônia Oriental, Sistemas de Produção, 4 - 2.ed. Versão Eletrônica, dez. 2006.

PETERSEN, J. et al. Gift from the past: Terra Preta and Prehistoric Amerindian Occupation in Amazonia. In: McEWAN, C. et al. (Ed.) Unknown Amazon, culture in nature in ancient Brazil. London: British Museum Press, 2001.

PORRO, A. O povo das águas: ensaios de etno-historia amazônica. Petrópolis: Vozes; São Paulo: Edusp, 1996.

RAPP PY-DANIEL, A. Arqueologia da morte no sitio Hatahara durante a fase Paredão. 2009. Dissertação (Mestrado) - Museu de Arqueologia e Etnologia, Universidade de São Paulo. São Paulo, 2009.

REBELLATO, L.; WOODS, W. I. A review of the Tupi expansion in the Amazon. In: 
causes and consequences of human migration: an evolutionary perspective. Cambridge: Cambridge Unversity Press, 2012. p.436-48.

ROOSEVELT, A. C. Moundbuilders of the Amazon: geophysical archaeology on Marajo Island, Brazil. San Diego: Academic Press, 1991.

Arqueologia amazônica. In: CUNHA, M. C. da. (Org.) História dos Índios no Brasil. São Paulo: Cia. das Letras, 1992, p.53-86.

SALOMÃO, R. de P. et al. Castanheira-do-brasil recuperando áreas degradadas e provendo alimento e renda para comunidades da Amazônia Setentrional. Boletim do Museu Paraense Emilio Goeldi Ciências Naturais, v.1, n.2, p.65-78, 2006.

SCHAAN, D. P. The Camutins Chiefdom: rise and development of complex societies in Marajó Island, Brazilian Amazon. 2004. Thesis (Ph.D) - University of Pittsburgh. Pittsburgh, 2004.

SCHMIDL, U. Viaje al rio de la Plata. 2.ed. Buenos Aires: Emecé Editores, 1945.

SHEPARD JUNIOR, G. H. Relatório emergencial sobre ameaças ao patrimônio histórico e arqueológico na região de Gurupá, PA. In: Relatório à Superintendência do $2^{\circ} S R$ / IPHAN. Belém, PA, 2012. (não publicado).

SOMBRÖEK, W. G. Amazon Soils: a reconnaissance of the soils of the Brasilian Amazon region. s. 1.: Wageninger center for Agricultural Publication and Documentation, 1966.

STAHL, P. W. Structural density of domesticated South American camelid skeletal elements and the archaeological investigation of prehistoric Andean ch'arki. Journal of Archaeological Science, v.26, n.11, p.1347-68, 1999.

STEWARD, J. H. Culture areas of the tropical forests. Handbook of South American Indians, v.3, p.881-99, 1948.

TAMANAHA, E. K. A tradição policroma no Baixo e Médio rio Solimões. 2012. Dissertação (Mestrado) - Museu de Arqueologia e Etnologia, Universidade de São Paulo. São Paulo, 2012.

UGARTE, A. Sertões de bárbaros: o mundo natural e as sociedades indígenas da Amazônia na visão dos cronistas ibéricos - séculos XVI - XVII. Manaus: Valer, 2009.

UJVARI, S. C. A história da humanidade contada pelos vírus: bactérias, parasitas e outros microorganismos. São Paulo: Contexto, 2009.

VALLE, R. B. M. Mentes graniticas e mentes areniticas: fronteiras geocognitivas nas gravuras rupestres do Baixo Rio Negro, Amazônia Setentrional. 2012. Tese (Doutorado em Arqueologia) - Museu de Arqueologia e Etnologia, Universidade de São Paulo. São Paulo, 2012.

VALLE, R.; MORAES, C. P. Relatório Arqueológico da RDS do rio Aripuanã -AM. SDS, Manaus - AM, 2007. (Relatório não publicado).

WOODS, W. I.; MCCANN, J. M. The anthropogenic origin and persistence of Amazonian dark earths. In: Yearbook. Conference of Latin Americanist Geographers. Conference of Latin Americanist Geographers, 1999. p.7-14. 
RESUMO - Este texto foi originalmente construído como parte de minha tese de doutorado. A proposta é discutir interpretações alternativas para pensar o surgimento de grandes contingentes populacionais na Amazônia antiga. Os motivos que levaram populações nativas a entrar em conflito por territórios. As causas de uma diminuição da população observada no registro arqueológico depois do ano mil de nossa era. O processo de formação de terra preta nos sítios arqueológicos. E principalmente a apresentação de uma proposta diferente da visão tradicional de complexidade sociopolítica necessariamente atrelada a populações mono agricultoras. Para apresentar essa proposta são utilizados dados arqueológicos coletados principalmente na região de Iranduba e no baixo rio Madeira, ambos no estado do Amazonas, Brasil.

Palavras-Chave: Ano mil, Conflito, Epidemia, Agricultura, Caça e coleta.

ABSTRACT - This text was originally built as part of my PhD dissertation. The goal is to discuss alternatives interpretations to rethink about the emergence of large populations in Ancient Amazonia. The reasons that lead native populations to go to war over territories. The causes of populational decline observed in the archaeological record after one 1000 years A.D. The formation process of Dark Earth in archaeological sites. And mainly to present a different ideia from the standard view of sociopolitical complexity related to one crop farming. To present this ideia we will use archaeological data collected mainly in the Iranduba region and the lower Madeira River, both in the State of Amazonas, Brazil.

KEYWORDS: 1000 years A.D, Conflict, Epidemics, Agriculture, Hunting and gathering.

Claide de Paula Moraes, arqueólogo, é doutorado em Arqueologia no Museu de Arqueologia e Etnologia da USP. É coordenador do curso de bacharelado em Arqueologia da Universidade Federal do Oeste do Pará, em Santarém. @ - claide29@gmail.com Recebido em $1^{\circ} .2 .2015$ e aceito em 10.2.2015.

I Faculdade de Arqueologia, Universidade Federal do Oeste do Pará, Santarém/PA, Brasil. 
